UDC 316.7

LBC 60.59

\title{
CURRENT IMAGE OF VOLGOGRAD AS SEEN BY THE STUDENT'S YOUTH ${ }^{1}$
}

\author{
Anton I. Shipitsyn \\ Volgograd State Socio-Pedagogical University, Volgograd, \\ Russian Federation \\ Anastasiya Yu. Marchenko \\ Volgograd State Socio-Pedagogical University, Volgograd, \\ Russian Federation
}

\begin{abstract}
The article touches upon specifics and features of students' perception of image of modern Volgograd. In the framework of the study the author interprets the image of the city as a complex structured phenomenon including people's subjective and stereotyped representations of socio-cultural, historical, socio-economic, political and other features of the territory. These representations can be formed both on the basis of specific emotions, personal impressions, and indirectly, from the materials of mass media, literary and cinematic sources, based on eyewitness stories, rumors and conjectures. At the same time, as the world experience shows, the economic development of this territory, the efficiency and legitimacy of political institutions, the state of the tourism industry, cultural life and demographic situation directly depend on how attractive the image of the city is for its residents and other members of society. Being a sophisticated and multi-component organization that can have a strong impact not only on the individual, but also on the mass perception and experience of the place and its identification, the image of the provincial city greatly affects the life strategies and migration attitudes of its residents. Especially it is true for young people and working population - graduates of schools and universities, young professionals. The authors describe the essence of the image positioning of the territory and the most important reasons for the wide spread of such practices, determines the value attitude of young people to Volgograd, proposes measures to improve the current image of the city. The researchers apply the results of quantitative and qualitative sociological research such as a questionnaire survey of students enrolled in 1-4 courses of various education fields of Volgograd State Socio-pedagogical University, interviews with experts.
\end{abstract}

Key words: youth, image of the city, regional identity, migration processes in the Russian province, urban studies, marketing of territories, Volgograd.

УДК 316.7

ББК 60.59

\section{АКТУАЛЬНЫЙ ИМИДЖ ВОЛГОГРАДА ГЛАЗАМИ СТУДЕНЧЕСКОЙ МОЛОДЕЖИ ${ }^{1}$}

\author{
Антон Игоревич Шипицин \\ Волгоградский государственный социально-педагогический университет, г. Волгоград, \\ Российская Федерация \\ Анастасия Юрьевна Марченко \\ Волгоградский государственный социально-педагогический университет, г. Волгоград, \\ Российская Федерация
}

Аннотация. Статья посвящена специфике и особенностям восприятия имиджа современного Волгограда студенческой молодежью. В рамках исследования имидж города трактуется в качестве сложно структу- 
рированного феномена, включающего в себя субъективные и стереотипизированные представления людей по поводу социокультурных, исторических, социально-экономических, политических и других особенностей данной территории, которые могут складываться как на основе конкретных эмоций, личных впечатлений, так и опосредованным образом, из материалов масс-медиа, литературных и кинематографических источников, на основе рассказов очевидцев, слухов и домыслов. При этом, как показывает мировой опыт, от того, насколько привлекателен имидж города для его жителей и остальных членов общества, напрямую зависит экономическое развитие данной территории, работоспособность и легитимность политических институтов, состояние туристической отрасли, культурная жизнь и демографическая ситуация. Представляя собой сложное поликомпонентное образование, способное оказывать сильное воздействие не только на индивидуальное, но и на массовое восприятие и переживание места, идентификацию с ним, имидж провинциального города в значительной степени влияет на жизненные стратегии и миграционные установки его жителей, прежде всего, молодежи и трудоспособного населения - выпускников школ и вузов, молодых специалистов. В статье описана сущность имиджевого позиционирования территории и наиболее важные причины широкого распространения подобной практики, определено ценностное отношение молодежи к Волгограду, предложены меры по улучшению актуального имиджа города. Использованы результаты количественного и качественного социологического исследования - анкетного опроса студентов, обучающихся на 1-4 курсах различных специальностей Волгоградского государственного социально-педагогического университета, интервью с экспертами.

Ключевые слова: молодежь, имидж города, региональная идентичность, миграционные процессы в российской провинции, urban studies, маркетинг территорий, Волгоград.

В условиях современного общества, когда темпы социокультурных и технических инноваций усиливаются, а скорость информационно-коммуникационных потоков все больше возрастает, особую значимость приобретает такая часть общества, как молодежь. В социальных науках сложилось множество различных подходов в изучении и трактовке категории «молодежь», обобщив которые, можно дать следующее универсальное определение: «Молодежь - это социально-демографическая, возрастная группа в интервале от 14 до 30 лет, проходящая стадию социализации, характеризующаяся отсутствием полного перечня основных социальных функций, определяющих статус взрослого (образование, работа, профессия, жилье, семья)» [Загребин web, 27]. Как наиболее мобильная, творчески активная и перспективная часть общества, стремящаяся к саморазвитию и повышению собственного статуса и значимости, сегодня именно молодежь становится доминирующим источником культурных инноваций, чьи мысли и чувства во многом определяют умонастроения общества и становятся образцом для подражания со стороны других поколений. Не случайно в прогнозах развития территории молодежь занимает одну из ключевых позиций, выступая в качестве ценного социального ресурса, потенциал которого определяет будущее общества и региона. Поэтому целью нашего исследования является изучение ценностных установок, стереотипных представлений, особенностей эмоционального и рационального восприятия волгоградской студенческой молодежью имиджа города Волгограда.

Актуальность исследования имиджа современного российского города обусловлена целым рядом причин, среди которых повышение роли нематериальных активов в рыночной экономике с преобладанием сферы услуг и знаний, трансформация характера труда, социокультурные последствия глобализационных процессов, бурный рост информации, распространение технологий и т. п. «Все это в совокупности повышает конкуренцию между городами за инвестиции, внимание властей, привлечение ресурсов развития, что, в свою очередь, требует от них самоопределения, поиска своего лица, выделения ключевых характеристик, ясного понимания миссии» [Шипицин, Щеглова 2017, 138-139]. Одним из средств конкурентной борьбы является формирование и постоянное поддержание позитивного имиджа города, который бы выгодно подчеркивал своеобразие и уникальность места, его инвестиционную привлекательность, улучшал социальное самочувствие его жителей.

В 2018 г. было начато исследование, связанное с изучением взаимосвязи современной региональной идентичности и молодежной 
миграции в Волгоградской области, участниками которого являются авторы данной статьи. Одной из ключевых задач проекта стал поиск и анализ точек соприкосновения региональной идентичности и имиджа города, который, согласно выдвинутой гипотезе, в неменьшей степени влияет на жизненные стратегии и миграционные установки выпускников школ, вузов и молодых специалистов, чем низкие социально-экономические показатели уровня жизни. Проблема оттока молодежи из Волгограда в другие регионы сегодня стоит особенно остро. Посредством сочетания количественного и качественного подходов в рамках исследования были проведены пилотажный анкетный опрос и экспертные интервью. Опрошено 169 респондентов в возрасте от 18 до 23 лет - студентов, обучающихся на 1-4 курсах различных специальностей Волгоградского государственного социально-педагогического университета. В ходе экспертных интервью было опрошено 8 специалистов, проживающих и работающих в Волгограде: 6 преподавателей волгоградских университетов (2 доктора философских наук, 2 кандидата философских наук, 2 кандидата социологических наук), 1 менеджер в сфере культуры, 1 урбанист. Помимо интерпретативного, компаративного, статистического анализа данных социологического исследования, был также задействован метод нетнографии.

Согласно определению И.С. Важениной, имидж города - это «набор убеждений и ощущений людей, которые возникают по поводу природно-климатических, исторических, этнографических, социально-экономических, политических, морально-психологических и др. особенностей данной территории» [Важенина $2006,83]$. Имидж представляет собой стереотипизированный образ в массовом сознании, структура которого имеет несколько уровней. «В этом образе слиты воедино представления людей по поводу социокультурных, исторических, социально-экономических, политических и других особенностей данной территории. При этом субъективное представление каждого человека о регионе может складываться как на основе конкретных личных впечатлений, так и опосредованным образом, из материалов масс-медиа, литературных и кинематографических источников, на основе рассказов очевидцев, слухов и домыслов» [Василенко 2016, 69]. Барбара Дженес также трактует территориальный имидж как многослойное образование, складывающееся из самых разнообразных компонентов: «национальные символы, цвета, одежда, типичные для этой территории постройки, музыка, литературные произведения, особенности политического устройства государства, обычаи, историческое наследие и многое другое» [Jenes 2008, 67]. Поэтому каждый аспект жизни города - от чистоты улиц и количества наружной рекламы до эффективности работы предприятий и уровня доверия к властям прямо или косвенно формирует имидж города, даже если мы этого не осознаем.

Как показывает мировой опыт, от того, насколько привлекателен имидж города для его жителей и остальных членов общества, напрямую зависит экономическое развитие территории, работоспособность политических институтов, состояние туристической отрасли, культурная жизнь и демографическая ситуация. «Помимо прочего обретение городом уникальной идентичности с известными и понятными отличиями способствует усилению его репутационного влияния, улучшению социально-психологического самочувствия жителей, культивации у них чувства гордости, уверенности, гармонии» [Шипицин, Щеглова $2017,139]$. Наконец, из города, имидж которого устойчиво позитивен, массово не уезжает молодежь. Именно поэтому имиджмейкинг сегодня является важнейшим направлением социальной политики, предметом внимания ученых, властей и общественности. Однако на практике проблема брендинга и профессионального позиционирования российских регионов не рассматривается местными властями в качестве приоритетной стратегической задачи. За редким исключением, имиджевые кампании в субъектах РФ проводятся стихийно и формально, без профессионального сопровождения и консультаций с ключевыми акторами, не имеют научного обоснования, не опираются на экспертные рекомендации и общественное мнение.

Формирование имиджа города является важным инструментом позиционирования территории на региональном, федеральном и международном уровне. Вместе с природными 
достопримечательностями, развитой инфраструктурой, материальными активами, уникальными историко-культурными ценностями, человеческим капиталом имидж сегодня является значимым фактором социально-экономического развития города, причем его привлекательность и положительная репутация зависят не только от реального потенциала, но и от того, как этот потенциал используется. Филипп Котлерсо своими коллегами в классическом исследовании, посвященном маркетингу мест, предложил 5 простых критериев разработки эффективного имиджа города. Образ должен соответствовать действительности, быть правдоподобным, простым, притягательным (из него должно явствовать, почему людям стоит жить, работать, инвестировать, приезжать в качестве туристов в данный город) и оригинальным [Котлер Ф. и др. $2005,214]$. Особо следует подчеркнуть, что обязательным условием яркого и сильного имиджа является его опора на идеи, ценности и образы, разделяемые большинством горожан. «Региональным властям важно понять: образ территории нельзя произвольно сконструировать, - он должен иметь социокультурные и исторические корни, опираться на реальный социально-экономический потенциал края» [Василенко 2016, 72]. Именно поэтому в разработке и реализации имиджевой стратегии должны принимать участие как местные, так и приглашенные ведущие эксперты: краеведы, историки, культурологи, философы, социологи, журналисты, представители власти и бизнеса.

Анализ современного состояния исследований проблемы проектирования и управления региональным имиджем показал, что на сегодняшний день социологами накоплена достаточно обширная теоретическая база, однако многочисленные идеи и практические наработки, посвященные имиджевому позиционированию территории, так и не оформились в единую теорию. А.В. Федотова в своей статье «Стратегия управления имиджем региона» определяет сущность и основания стратегии управления имиджем региона, анализирует целевую аудиторию, ключевые количественные и качественные характеристики территории [Федотова 2018, 57-61]. И.В. Варламова рассматривает имидж региона как ре- путационный капитал, подчеркивая, что стратегии имиджирования территории в конечном счете направлены на решение прагматических задач, таких как «обеспечение территории социально-рентабельной репутации, возникновение «прибавленной стоимости», увеличение позитивной эмоциональной капитализации региона в восприятии целевыми группами» [Bapламова 2014, 167-172]. В социологическом исследовании Н.Г. Чевтаевой, А.В. Ручкина, Т.А. Сергеевой рассматриваются эмоциональные ассоциации, фиксируются и анализируются социальные и экономические проблемы, влияющие на имидж Свердловской области в глазах жителей [Чевтаева, Ручкин, Сергеева 2017, 138-143]. В Волгограде вопрос имиджевого позиционирования города изучался целым рядом исследователей, в частности Д.П. Фроловым, В.А. Шишковым и др. (см.: [Фролов, Шишков 2013, 22-32]), а в 2010 г. под руководством профессора Волгоградского государственного университета О.В. Иншакова была разработана маркетинговая стратегия развития Волгограда до 2020 года [Иншаков (ред.) 2011].

Следует признать, что в последние годы проблема формирования позитивного имиджа Волгограда все чаще привлекает внимание не только ученых, но и городских властей, журналистов, широкой общественности. Из каких составляющих складывается имидж Волгограда в сознании горожан? Как волгоградцы относятся к образу родного города? Как и кто может сделать имидж Волгограда привлекательным для жизни и инвестиций? Какое влияние оказывает негативный имидж Волгограда на многолетний массовый отток из региона молодежи и трудоспособного населения? Эти и другие вопросы перестают быть риторическими и приобретают все большую теоретическую и практическую значимость, требуют активного осмысления и заинтересованного обсуждения.

Во всем мире наш город известен как Сталинград по причине исторических событий Второй мировой войны. Волгоград узнают по абрису монумента «Родина-мать зовет!» на Мамаевом кургане. Эта фигура, безусловно, являясь эмблемой нашего города, ее основным символом, с одной стороны, мощно идеологизирована, с другой - стереотипи- 
зирована. Между тем даже такой значимый для города культурно-символический ресурс, как героическое прошлое Сталинградской битвы, не получает должной поддержки и модернизации. Невнимание городских властей к достойной символической презентации памяти о победе в Сталинградской битве приводит к таким происшествиям, как падение фигуры памятника «Комсомольцам - защитникам Сталинграда» в апреле 2009 г., вандализм в отношении скульптурной фигуры Девочки Милы на Солдатском поле в январе 2014 г., хищение средств, выделенных на реставрацию памятника героям-связистам времен Великой Отечественной войны «Ролик» в 2018 г. и т. д. К сожалению, именно подобные факты, а также видеосюжеты, аналитические материалы и статьи с заголовками «В Волгограде каждый день закрывается по 10 предприятий», «Волгоград признан одним из худших городов России по качеству жизни» и т. п., транслируемые в СМИ и Интернете, формируют негативный имидж города.

Основной целью количественного исследования восприятия молодежью имиджа Волгограда было не столько провести поверхностный сбор ассоциаций, связанных с образом Волгограда, сколько попытаться проследить более динамично меняющийся, а следовательно, менее доступный для анализа субъективно-личностный, эмоциональный компонент в ответах респондентов. Кроме того, нами сознательно было сделано техническое обобщение понятий «имидж Волгограда» и «имидж региона». Поскольку административные границы между областным центром и граничащими населенными пунктами достаточно условны, подвижны и сложились довольно поздно, то события и факты прошлого (основание Царицына, период Гражданской войны, индустриализация, Сталинградская битва и т. д.), повлиявшие на формирование имиджа данной территории, в равной степени касаются истории и современности как города-миллионника, так и близлежащих к нему районов.

По итогам исследования две трети опрошенных студентов назвали себя волгоградцами (можно предположить, что значительная доля респондентов не считают себя таковыми в связи с тем, что приехали на учебу из других населенных пунктов), а 76 \% уверенно связывают свое будущее с волгоградским регионом. Символика Волгограда во многом связана с военным прошлым нашего города: более половины респондентов назвали основным символом города скульптуру «Родинамать зовет!», Мамаев курган в целом и Музей-панораму «Сталинградская битва». Что касается собственно Сталинградской битвы, то она признается большинством опрошенных в качестве единственного наиболее значимого события в истории нашего города (69 \%). С одной стороны, это объясняется действительным колоссальным фактическим и символическим значением данного события в истории нашей страны, о чем также пишет в своей статье известный урбанист Е.Г. Трубина, отмечая, что «Волгоград, будучи впечатляющим примером социалистической традиции модернистского планирования, становится для многих хранилищем "советских" воспоминаний как в силу своей городской структуры, так и в силу травм Второй Мировой войны» [Trubina 2010, 107]. С другой стороны, преобладание советских коннотаций в восприятии Волгограда можно также объяснить слабой осведомленностью молодежи о невоенных страницах волгоградского прошлого, например, царицынского периода. Так, к другим событиям, называемым респондентами в качестве значимых и выдающихся, относятся прошедшие в Волгограде матчи Чемпионата мира по футболу (2018 г.), строительство Волжской ГЭС (1961 г. окончания строительства), основание Сарепты и деятельность немецких колонистов (вторая половина XVIII в.), основание тракторного завода (1930 г.).

Представляют интерес также ответы на вопрос о наиболее известных личностях, внесших вклад в формирование и развитие имиджа Волгограда. $27 \%$ опрошенных назвали имя И.В. Сталина, 20 \% связывают имидж города и региона с деятельностью известной спортсменки Е.Г. Исинбаевой, на третьем месте со значительным отрывом от лидеров Е.В. Вучетич, архитектор, проектировавший скульптуру «Родина-мать зовет!» на Мамаевом кургане (8\%). Интересно, что при столь явном внимании к личности И.В. Сталина подавляющее большинство опрошенных (78 \%) высказываются однозначно против систематически обсуждаемых в СМИ инициатив пе- 
реименования города и возвращения ему имени коммунистического вождя народов. Признавая значимость его вклада в ход Сталинградской битвы, большая часть молодежи связывает свое будущее с жизнью в современном Волгограде, устремленном в будущее, а не в городе-музее кровопролитной войны, названном по имени весьма противоречивого исторического деятеля. В поддержку переименования высказалось около десятой доли опрошенных.

Уровень собственных знаний об истории и культуре Волгограда большая часть опрошенных назвала средним (59 \%). При этом подавляющее большинство респондентов (более чем 90 \%) убеждены в необходимости введения в учебные планы образовательных учреждений нашего города специального курса, посвященного дополнительному изучению истории и культуры Волгограда и региона в целом. Возможно, это связано с тем, что основной упор в процессе обучения в волгоградских школах и вузах традиционно делается на фактологии Сталинградской битвы, в то время как другие моменты истории региона (основание города, история дореволюционного Царицына, период Гражданской войны и т. д.) оказываются вне внимания и последовательного изучения.

Оценка темпов социально-экономического и культурного развития Волгограда и области негативна и говорит о том, что с точки зрения молодежи наш регион относится скорее к деградирующим, нежели к активно развивающимся субъектам РФ. Более трех четвертей опрошенных (78\%) оценивают данные темпы как низкие. О высокой или, по крайней мере, средней оценке развития города высказались менее пятой части респондентов. При этом культурный уровень респонденты оценивают более позитивно, чем уровень социально-экономического развития. К числу существенных недостатков респонденты относят плохие дороги, нерешенность транспортной проблемы в чрезвычайно протяженном городе, низкое качество услуг в сфере ЖКХ, сложную экологическую ситуацию, нехватку парков, спортивных комплексов, скверов и озеленения, коррупцию.

Судя по ответу на вопрос, является ли Волгоград городом, благоприятным для раз- вития и самореализации современной молодежи, значительная доля опрошенных респондентов (37\%) убеждена, что благоприятные условия для самореализации молодежи в нашем городе отсутствуют. Еще больше респондентов затруднились ответить (42\%). Позитивно ответили на этот вопрос только пятая часть опрошенных (21\%). В целом можно утверждать, что имидж Волгограда в глазах студентов Волгоградского государственного социально-педагогического университета умеренно негативный. Среди наиболее часто используемых респондентами отрицательных характеристик при описании города преобладают (по убыванию): «депрессивный», «серый», «бедный», «неперспективный», «длинный», «криминальный», «грязный». Самые распространенные положительные качества: «город-герой», «культурный», «спортивный», «красивый».

Для верификации полученных в результате анкетирования студентов данных в ходе экспертных интервью мы просили респондентов ответить, среди прочего, на те же вопросы, что содержались в анкете. Мнения экспертов важны не только для получения более полной и компетентной оценки имиджа Волгограда в контексте острой для города проблемы оттока молодежи, но и для выработки предложений и мер по его улучшению, а также для верной интерпретации ответов, состоящих из субъективных суждений, эмоциональных оценок, коллективных представлений, ассоциаций и стереотипов.

Проблема наличия негативного имиджа города и его возможного влияния на складывание у молодежи миграционных установок, связанных с желанием уехать из Волгограда, признается всеми экспертами. Более того, один из экспертов отметил, что чувство нелюбви и пренебрежительного отношения к Волгограду является типичной чертой его жителей.

P: Я бы согласился с тем, что волгоградиь действительно не любят свой город и это некоторая констатация факта. И речь идет не просто о населении рядовом, здесь все агенты имеются в виду, и власть тоже, и все, кто могут что-то делать и подходит под этот кониепт волгоградиа. Все не любят свой город, речь идет 
именно об этом. Все участники этого процесса (философ, преподаватель вуза).

Имидж Волгограда, как и любого современного российского города, является сложным поликомпонентным образованием, способным оказывать сильное воздействие как на индивидуальное, так и на массовое восприятие и переживание места, идентификацию с ним. В отсутствии реальных шагов по реализации стратегии маркетинга территории имидж города складывается стихийно из фактов, событий, образов, характеристик, упоминаемых в СМИ и Интернете, и прочно закрепляется на рациональном и эмоциональном уровне сознания.

P: Мне кажется, что когда речь идет об имидже, то важнее всего вот эта предварительная работа по маркированию ситуаций, символики. Вот эта маркировка, ярлычки, которые мы понавешали, - это и есть материал, из которого соберется имидж, и поэтому здесь важна эта предварительная работа кропотливая, чтобы посмотреть, из чего собирается имидж. Вот то же недоверие власти и этот рейтинг, который из года в год вывешивается, это такое клеймо уже на нашем регионе, потому что степень удовлетворенности регионом жителей, уровень соииального самочувствия, уровень доверия власти, все эти рейтинги смотрят и каждый себя там находит. Вот это уже маркер такой, который в имидже многое испортит. Поэтому, мне кажется, вот такие вещи важны (зав. кафедрой университета).

Следует отметить, что с 2011 по 2018 г. в городе действовала «Маркетинговая стратегия развития территории городского округа город-герой Волгоград до 2020 года», целью которой было: «продвижение уникальных преимуществ Волгограда с учетом всех имеющихся и потенциальных ресурсов и устойчивый рост его конкурентоспособности в системе территориального разделения труда посредством качественного улучшения делового, инвестиционного, инновационного, культурного, научного, спортивного и рекреационного имиджа Волгограда на муниципальном, региональном, федеральном и международном уровнях» [Постановление Администрации Волгограда от 10.10.2011... web]. Как показало время, практическая реализация страте- гии либо не осуществлялась в должной мере, либо была неэффективной и не способствовала решению поставленных задач в области улучшения имиджа и репутации города, формированию положительных ассоциаций, символов, брендов, несмотря на то, что волгоградскими учеными была разработана детальная поэтапная модель механизма ее реализации [Фролов, Шишков 2013, 23]. С точки зрения Д.П. Фролова и В.А. Шишкова, институциональная практика имиджевого позиционирования Волгограда, содержание которой зафиксировано в официальном документе, осложнялась по следующим причинам. Во-первых, нежелание городской администрации задействовать гражданское общество при решении вопросов формирования и поддержания имиджа города, во-вторых, неуклонное расширение спектра объектов продвижения, в-третьих, формализованность и завершенность маркетинговой стратегии развития Волгограда своим форматом ограничивает возможности внесения изменений, адаптации к новым трендам, оперативной апробации креативных идей [Фролов, Шишков 2013, 24].

Неудачный опыт внедрения территориального маркетинга также показал, что при разработке мер по формированию позитивных имиджевых качеств Волгограда следует учитывать прежде всего специфику нашего города, связанную с его зависимостью от образов и символов героического прошлого, отсылающих к теме Сталинградской битвы и многочисленных жертв и вытесняющих несоветские элементы идентичности. Поэтому первостепенное значение, помимо улучшения социально-экономической ситуации, оздоровления общественно-политических отношений, имеет информационная и культурно-символическая политика, направленная на отказ от чрезмерной и примитивной эксплуатации тем победы, памяти, патриотизма и использования иных уникальных ресурсов. Здесь показательны следующие высказывания экспертов:

P: У нас от всего этого героического прочлого и образа Волгограда какая-то есть, не знаю, идеологическая рутина. Обычно власть заинтересована в своем имидже, она ищет какие-то новые методы привлечения к себе положительного 
внимания. У нас это совершенно не развито. Этот военный образ эксплуатируется непрерывно, и такое ощущение, что мы в плену у этого герочческого образа и считается, что больше и не надо (зав. кафедрой университета).

P: Это наша общероссийская проблема, потому что современная российская идеология во многом строится на Дне Победы. Я думаю, что мы заложники этой темы. Это чуть ли не единственный общенародный скрепляющий такой ритуал, праздник. Новый год, День Победы, и других я не нахожу фундаментальных таких событий, которые могли бы служить объединяюшим фактором. В этом смысле Волгоград во многом своеобразный узел в этой сети по формированию общероссийской идентичности. И хотя это надоело, если это из сети вынешь, то все рассыплется (философ, преподаватель вуза).

P: Просто очень обидно, что власть не использует потенциал, например, вузов, какой-то креативный потенииал. Никто же не говорит, что война и победа должны быть забыты, но она не ищет новых способов формирования, развития региона (зав. кафедрой университета).

P: Это хороший ресурс - регион-победитель. Но его можно использовать не только как символ военных побед. Могут быть победы спортивные, трудовые, творческие. Экстраполировать нужно на другие области (социолог, декан факультета).

Подводя итоги теоретической и практической части нашего исследования, можно сделать следующие промежуточные выводы. Привлекательность города зависит не только от его реальных количественных и качественных характеристик, культурно-исторического потенциала или четко выраженной миссии, но и от того, как он оценивается и воспринимается жителями, и в первую очередь молодежью. Являясь нематериальным активом, имидж оказывает вполне материальное влияние на развитие городской среды, конкурентоспособность, уровень и качество жизни горожан. Волгоградская студенческая мо- лодежь воспринимает свой город сквозь призму его сталинградского героического прошлого и оценивает сложившийся имидж Волгограда как не очень благоприятный для создания семьи, успешной профессиональной карьеры, творческой самореализации, что стало устойчивым тиражируемым стереотипом, формирующим ценностное отношение студентов к городу, определяя их идентичность и жизненные стратегии. Укоренившиеся среди широких слоев молодежи депрессивно-пессимистические установки «в Волгограде делать нечего», «депрессивный и отсталый город», «самый бедный город-миллионник» являются, на наш взгляд, неявной причиной массового отъезда выпускников школ и вузов в Москву, Санкт-Петербург, Краснодар, Сочи и другие современные с точки зрения имиджевого позиционирования российские города. И если объективным факторам эмиграции из провинциальных городов в столичные центры противостоять практически невозможно, они существовали всегда в силу разных условий развития территорий (безработица, отсутствие культурной жизни, плохое качество образования, медицинских услуг, благоустройства и т. д.), то проблема рекламы и позиционирования города с помощью профессионально разработанного имиджа относится к числу решаемых и хорошо изученных. Мы ограничимся лишь некоторыми общими замечаниями по улучшению имиджа и репутации Волгограда:

- позиционирование города в информационно-коммуникационном пространстве должно быть долгосрочным, системным, адаптивным, непротиворечивым и иметь четкую концептуальную основу;

- разработка и реализация программы имиджевого позиционирования должна включать в себя большую предварительную работу по выявлению основных конкурентных преимуществ и уникальных характеристик Волгограда с последующим формированием положительных ассоциаций и привлекательных символов территории;

- решение проблемы совершенствования имиджа города должно осуществляться в формате краудсорсинга, то есть с привлечением всех заинтересованных участников простых горожан, местных и приглашенных ведущих экспертов: краеведов, урбанистов, 
культурологов, философов, социологов, журналистов, представителей власти и бизнеса;

- необходимо отказаться от чрезмерной и примитивной эксплуатации тем Сталинградской битвы, войны, победы, патриотизма и использовать иной символический капитал, которым, как полагают многие специалисты, может быть культура;

- обязательным условием проектирования и внедрения современного имиджа Волгограда должен быть учет общественного мнения на предмет лояльности новым символам, образам, идеям, ценностям, которые должны быть позитивными и консолидирующими горожан;

- продвижение перспективных идей развития города, презентация и обсуждение стратегии имиджевого позиционирования должны иметь максимально широкий характер, что требует развития регионального медиапространства и системы местных коммуникаций.

\section{ПРИМЕЧАНИЕ}

${ }^{1}$ Исследование выполнено при финансовой поддержке РФФИ и Волгоградской области в рамках научного проекта № 18-411-343002.

The study was supported by the Russian Foundation for Basic Research (RFBR) in the framework of research project no. 18-411-343002.

\section{СПИСОК ЛИТЕРАТУРЫ}

Важенина 2006 - Важенина И.С. Имидж и репугация территории как основа продвижения в конкурентной среде // Маркетинг в России и за рубежом. 2006. № 6. С. 82-98.

Варламова 2014 - Варламова И.В. Имидж региона как репугационный капитал // Вестник Чувашского университета. 2014. № 1. С. 167-172.

Василенко 2016 - Василенко И.А. Возможности инновационных технологий территориального брендинга для формирования современного имиджа российских регионов // Власть. 2016. № 1. С. 68-73.

Загребин web- Загребин В.В. Подходы к определению категории «молодежь» [Научно-методический электронный журнал «Концепт». 2014. № 2 (февраль). С. 26-30] // https://e-koncept.ru/ 2014/14030.htm.

Иншаков (ред.) 2011 - Иншаков О.В. (ред.). Маркетинговая стратегия развития Волгограда до 2020 года в условиях преодоления послед- ствий кризиса. Волгоград: Изд-во ВолГУ, 2011.

Котлер и др. 2005 - Котлер Ф., Асплунд К., Рейн И., Хайдер Д. Маркетинг мест: привлечение инвестиций, предприятий, жителей и туристов в города, коммуны, регионы и страны Европы. СПб.: Стокгольмская школа экономики в Санкт-Петербурге, 2005.

Постановление Администрации Волгограда от 10.10.2011... web - Постановление Администрации Волгограда от 10.10.2011 № 3072 «Об угверждении маркетинговой стратегии развития территории городского округа город-герой Волгоград до 2020 года» // http://docs.cntd.ru/ document $/ 446503500$.

Федотова 2018 - Федотова А.В. Стратегия управления имиджем региона // Общество: политика, экономика, право. 2018. № 1. С. 57-61. Фролов, Шишков 2013 - Фролов Д.П., Шииков В.А. Маркетинговая стратегия региона в действии (опыт Волгоградской области) // Региональная экономика: теория и практика. 2013. № 31 . C. 22-32.

Чевтаева, Ручкин, Сергеева 2017 - Чевтаева Н.Г., Ручкин А.В., Сергеева Т.А. Анализ восприятия имиджа региона в общественном сознании (на примере Свердловской области) // Вопросы управления. 2017. № 2 (45). С. 138-143.

Шипицин, Щеглова 2017 - Шипииин А.И., Щеглова Л.В. Культурный брендинг Волгограда: условия и проблемы // Каспийский регион: политика, экономика, культура. 2017. № 4 (53). C. $137-145$.

Jenes 2008 - Jenes $B$. Reconsidering the measurement of country image-theory and practice // FIKUSZ 2008 Business Sciences - Symposium for Young Researchers: Proceedings. Budapest: Obuda University, Keleti Faculty of Business and Management, 2008. P. 65-80.

Trubina 2010 - Trubina E. The reconstructed city as rhetorical space: The case of Volgograd // Remembering, Forgetting and City Builders. Farnham: Ashgate Publishing Ltd, 2010. P. 107-120.

\section{REFERENCES}

Vazhenina I.S., 2006. The image and reputation of the territory as the basis for advancement in a competitive environment. Marketing $v$ Rossii $i$ za rubezhom, vol. 6, pp. 82-98.

Varlamova I.V., 2014. The image of the region as reputational capital. Vestnik Chuvashskogo universiteta, vol. 1, pp. 167-172.

Vasilenko I.A., 2016. Possibilities of innovative technologies of territorial branding for the 
formation of a modern image of Russian regions. Vlast', vol. 1, pp. 68-73.

Zagrebin V.V., 2014.Approaches to the definition of the category “youth". Kontsept, no. 2, pp. 26-30. URL: https://e-koncept.ru/2014/14030.htm.

Inshakov O.V. (ed.), 2011. Marketing strategy of development of Volgograd till 2020 in the conditions of overcoming the consequences of crisis. Volgograd, Izd-vo VolGU.

Kotler F., Asplund K., Reyn I., Khayder D., 2005. Marketing places. Attracting investments, businesses, residents and tourists to cities, communes, regions and countries of Europe. Saint-Petersburg, Stokgol'mskaya shkola ekonomiki v Sankt-Peterburge.

Resolution of the Administration of Volgograd of October 10, 2011 No. 3072 “On Approving the Marketing Strategy of Developing the Territory of the City District of Hero City Volgograd till 2020". URL: http://docs.cntd.ru/document/446503500.

Fedotova A.V., 2018. Management strate gyfortheimage of the region. Obshchestvo: politika, ekonomika, pravo, vol . 1, no. 1, pp. 57-61.
Frolov D.P., Shishkov V.A., 2013. Marketing strategy of the region in action (the experience of the Volgograd region). Regional'naya ekonomika: teoriya i praktika, no. 31, pp. 22-32.

Chevtaeva N.G., Ruchkin A.V., Sergeeva T.A., 2017. Analysis of the perception of the image of the region in the public consciousness (on the example of the Sverdlovsk region). Voprosy upravleniya, no. 2 (45), pp. 138-143.

Shipitsin A.I., Scheglova L.V., 2017. Cultural branding of Volgograd: conditions and problems. Kaspiyskiy region: politika, ekonomika, kul'tura, no. 4 (53), pp. 137-145.

Jenes B., 2008. Reconsidering the measurement of country image - theory and practice. FIKUSZ 2008 Business Sciences - Symposium for Young Researchers: Proceedings. Budapest: Obuda University, Keleti Faculty of Business and Management, pp. 65-80.

Trubina E., 2010. The reconstructed city as rhetorical space: The case of Volgograd. Remembering, Forgetting and City Builders. Farnham: Ashgate Publishing Ltd., pp. 107-120.

\section{Information about the Authors}

Anton I. Shipitsyn, Candidate of Sciences (Philosophy), Associate Professor, Department of Philosophy and Cultural Studies, Volgograd State Socio-Pedagogical University, Prosp. Lenina, 27, 400131 Volgograd, Russian Federation, ship81@mail.ru, https://orcid.org/0000-0002-9915-3191

Anastasiya Yu. Marchenko, Candidate of Sciences (Philosophy), Associate Professor, Department of Philosophy and Cultural Studies, Volgograd State Socio-Pedagogical University, Prosp. Lenina, 27, 400131 Volgograd, Russian Federation, sundayk@inbox.ru, https://orcid.org/0000-0003-4002-6830

\section{Информация об авторах}

Антон Игоревич Шипицин, кандидат философских наук, доцент кафедры философии и культурологии, Волгоградский государственный социально-педагогический университет, просп. Ленина, 27, 400131 г. Волгоград, Российская Федерация, ship81@mail.ru, https://orcid.org/0000-0002-9915-3191

Анастасия Юрьевна Марченко, кандидат философских наук, доцент кафедры философии и культурологии, Волгоградский государственный социально-педагогический университет, просп. Ленина, 27, 400131 г. Волгоград, Российская Федерация, sundayk@inbox.ru, https://orcid.org/0000-0003-4002-6830 